\title{
Acolhimento como estar junto: vidas que importam
}

\section{Welcoming as to be together: lives that matter}

Flávio Breno Cruz Formigosa ${ }^{1}$

1 Acadêmico. Universidade do Estado do Rio de Janeiro (UERJ), Brasil. E-mail: brenocruz.uerj@outlook.com

Recebido em: 08/01/2020 | Aprovado em: 11/03/2020

DOI: $10.12957 /$ interag.2019.47712

\section{Resumo}

O presente relato de experiência tem o objetivo de expor os trabalhos realizados pelo Laboratório de Fenomenologia e Estudos e Psicologia Existencial (LAFEPE) em relação à temática do suicídio. Pretendo ressaltar a relevância e necessidade de intervenções de cunho clínico relacionadas à questão do suicídio. Para isso, além da apresentação da discussão referente ao tema do suicídio, tenho o intuito de: descrever quais foram os estudos feitos pelo LAFEPE e o referencial teórico utilizado nas pesquisas, o que entendemos como processo psicoterapêutico, quais são as iniciativas realizadas pelo laboratório, quais as dificuldades de se falar sobre um assunto por vezes escuso, marginalizado e entendido como tabu e, por fim, como as práticas da extensão contribuíram para minha formação como estudante de psicologia, de modo a expressar o trabalho acadêmico da extensão como retorno à comunidade interna e externa à UERJ.

Palavras-chave: Suicídio; Psicologia Fenomenológica Existencial; Núcleo de Atendimento Clínico; Extensão; Acolhimento

Área temática: Saúde.

Linha de extensão: Saúde Humana.

\begin{abstract}
This experience report aims to expose the work done by the Laboratory of Phenomenology and Studies and Existential Psychology (LAFEPE) in relation to the subject of suicide. I intended to emphasize the relevance and necessity of clinical interventions related to the issue of suicide. For this, besides the presentation of the discussion about the subject of suicide, my goal is: to describe which studies were done by LAFEPE and the theoretical framework used in the research, what I meant as a psychotherapeutic procedure, what are the initiatives undertaken by the laboratory, what are the difficulties of speaking about a subject that is sometimes scarce, marginalized and understood as taboo, and finally, how extension practices contributed to my education as a student of psychology, in order to express the academic work of extension as a return to the internal and external community of UERJ.
\end{abstract}

Keywords: Suicide; Existential Phenomenological Psychology; Clinical Care Center; Extension; 


\section{Introdução}

A Organização Mundial de Saúde (World Health Organization - WHO) ${ }^{1}$ em 2019, diz que, apesar de ter aumentado, em um intervalo de cinco anos, o número de países com estratégias nacionais de prevenção ao suicídio, desde a publicação do primeiro relatório global sobre essa questão, enxerga como ainda insatisfatório o comprometimento das nações para o estabelecimento de práticas de prevenção. Nota-se que há um engajamento global para refletir sobre a efetividade das medidas tomadas sobre esse aspecto muito caro para os órgãos de saúde na modernidade ocidental.

No Brasil, o Ministério da Saúde ${ }^{2}$ reconhece o suicídio como uma questão de saúde pública. Algo multifacetado, que atinge as mais diversas camadas da população. A partir da esfera pública, pensa que ao estruturar-se enfaticamente com práticas de atuação de âmbito coletivo, pode articular modos de prevenção a partir da atenção dada aos sinais de alerta e à formação de redes de apoio mútuo.

A psicologia, atenta à complexidade e delicadeza desse assunto, de modo algum se posiciona de modo indiferente. O Conselho Federal de Psicologia, ${ }^{3}$ mais especificamente desde 2013, tem tentado intensificar a abertura de espaços de diálogo para repensar a lida com a morte voluntária, de maneira a reavaliar as próprias bases que fundamentam suas práticas.

Falar sobre suicídio é algo que instiga as pessoas e o laço social de modo geral a entender que há um problema na sociedade, que se configura por determinados fatores e que, portanto, exige resolubilidade segundo determinadas diretrizes. Tal inquietação mostra-se como audacioso desafio quando constatamos que pensar métodos de resolução para a questão do suicídio pela via do total controle através do imperativo do fazer viver é equivalente a tentar resolver a questão da própria morte. É possível essa empreitada? Parece que mais do que o morrer, o ato de provocar a própria morte mobiliza as pessoas de tal modo, que até mesmo esquecemos que a finitude inexoravelmente desde sempre é algo nosso. Tratar a morte como algo estranho não afasta de nós o fato que um dia a morte irá se apresentar. Sabemos que não só podemos como vamos morrer, uma vez que possuindo o caráter efêmero na existência, sermos eternos não é algo alcançável pela vontade humana, por mais que assim o quiséssemos por vezes. A questão é que quando nos remetemos ao suicídio, esse modo de morrer que é autoprovocado ganha um aspecto de não natural, de maneira a dificultar que falemos sobre esse tema sem cairmos em 
perspectivas moralizantes. Outro desafio se apresenta: como estar junto para acolher sem preconceitos aquele que pensa em se matar se de antemão já possuímos um juízo sobre viver e morrer? Uma preconcepção, seja qual for o conteúdo, inviabiliza que uma escuta atenta aconteça. Muitas vezes suspender as concepções sobre esse tema pode soar como ser indiferente ou propor apologias ao ato. $\mathrm{O}$ que se discute é como estar alinhado genuinamente ao que se apresenta na dinâmica das situações de suicídio.

Talvez falar sobre querer morrer seja difícil, porque diz respeito a uma possibilidade que está para todos indiscriminadamente, ou talvez porque expressa o caráter finito da existência, apontando dessa maneira a fragilidade da vontade humana em subjugar o mundo, inclusive a morte. Independente dessas conjecturas corresponderem ou não ao que está em jogo na dinâmica pessoal, poder falar sobre o tema é essencial para que modos outros de se pensar possam se configurar naquilo que entendemos na relação entre o viver e o morrer.

\section{Grupo LAFEPE}

Diante das questões suscitadas anteriormente, faz-se necessário apresentar como o projeto no qual faço parte tem pensado e trabalhado sobre o tema do suicídio. O LAFEPE tem buscado, desde 2016, voltar sua atenção para a atuação clínica psicológica em situações de suicídio, tanto para os que pensam em tirar a própria vida, como também para os que tiveram pessoas próximas que cometeram o ato.

Uma vez que pesquisas 1 apontam alta incidência de suicídio em pessoas na facha etária entre 15 e 29 anos, e estando a população da UERJ nesses parâmetros, percebemos que eram imprescindíveis ações em resposta a essa problemática. O LAFEPE após longo estudo e pesquisa criou o Núcleo de Atendimento Clínico (NAC) ${ }^{4}$ no espaço do Serviço de Psicologia Aplicada (SPA) da UERJ, o núcleo atua na prevenção, no tratamento e na "posvenção."

O ensino, pesquisa e extensão estão presentes de modo indissociável em nossas atividades. Por meio de pesquisas podemos perceber que historicamente o suicídio foi apreendido de maneiras diversas. ${ }^{5}$ Entender esse fenômeno como necessariamente relacionado ao pecado, crime, doença mental ou violência contra si próprio, entre outros, são compreensões morais e estigmatizantes, com única diferença na variação dos referenciais. Perspectivas religiosas, jurídicas 
ou psicopatologizantes são generalizações que perdem de vista a dinâmica singular daquele que pensar em tirar a própria vida.

Para aproximar-se psicoterapeuticamente da experiência daqueles que pensam em tirar a própria vida, os referenciais teóricos adotados pelo grupo são o método fenomenológico e a filosofia existencial. ${ }^{6}$ Frente à indeterminação que é a existência, tais correntes do pensamento pretendem suspender concepções apriorísticas sobre a dinâmica humana para que desse modo a escuta psicoterapêutica seja limpa, isto é, esteja atenta e afinada com aquilo que se apresenta em situações de suicídio.

Fruto de extenso estudo sobre o tema, o LAFEPE tem feito publicações de artigos, um livro6, organização e participação de eventos dentro e fora da UERJ, cursos de extensão, participações em congressos em escala estadual, nacional e internacional. Em 2019, quatro participantes do grupo, incluindo a coordenadora, foram a Buenos Aires, Argentina, fazer exposições orais sobre temáticas relacionadas ao suicídio. Também em 2019, nosso projeto ofereceu uma eletiva com grande número de inscritos no curso de psicologia para que os alunos pudessem ter familiaridade com esse assunto em sua formação. Criamos um grupo de estudos que tem agregado alunos de outros cursos da UERJ Maracanã e também comunidade externa interessada em refletir sobre a temática. Nossa atuação tem acontecido no SPA UERJ com atendimentos individuais com pessoas que pensam em se matar, assim como aqueles que tiveram proximidade com situações de suicídio. Também fazemos acolhimento em outros espaços da UERJ, como o NACE, e eventuais tentativas de suicídio em que participantes do grupo estejam disponíveis. Ademais estivemos em escolas coordenando rodas de conversas de caráter informativo juntamente com propostas de terapia em grupo. O que os membros do LAFEPE têm percebido nesses espaços é que falar sobre o tema de modo algum tem se mostrado como suposto gatilho para o suicídio; pelo contrário, tem sido algo libertador e construtivo para jovens, que ao trazerem o assunto, segundo relatam, costumam ser ignorados ou até mesmo silenciados.

\section{Acolher como estar junto}

As diversas inserções do grupo têm batalhado para desconstruir preconceitos e tabus sobre o suicídio presentes no senso comum e também no próprio âmbito acadêmico. A própria psicologia é questionada em sua epistemologia e metodologia para que possamos realizar um exame crítico de quais parâmetros embasam o modo que apreendemos a lida humana com sua 
finitude, esta que desde sempre está posta. A proposta do grupo é poder se aproximar das situações que envolvem suicídio, tentando suspender ao máximo concepções apriorísticas que impossibilitem acompanhar genuinamente as pessoas nos atendimentos. Cada situação sempre será um caso particular, contendo uma miríade de singularidades; portanto, não há como sustentar a concepção de que o que fazemos é construir uma técnica de como atuar em determinadas situações. Nosso exercício constante é caminhar em direção diametralmente oposta, isto é, afastar-se dos juízos morais vigentes para oferecermos um atendimento sério, digno, respeitoso e principalmente, atento.

$\mathrm{Na}$ modernidade, a lógica de manutenção da vida levanta um questionamento fundamental para pensarmos atendimento: é plenamente benéfico pensar prevenção como estabelecimento de controle? O que determina o campo limítrofe entre tutelar o viver e sustentar a tensão no querer morrer para que talvez vida ganhe outros contornos? Permanecer no tensionamento não implica na indiferença com a possibilidade que alguém venha a se matar, mas sim a consciência que sendo essa escolha algo que só cabe em última instância àquele que é acolhido, o trabalho psicoterapêutico é a meditação em que o outro possa aparecer para si, para que assim ganhe outros sentidos. Se o intuito é antever para controlar perde-se o contato imediato. Valer-se de fatores de risco, sinais de potenciais suicidas é reforçar estigmas que afastam o processo de caminhar ao lado, já que buscar o controle é se antecipar ao outro. Entender o aspecto multifacetado do suicídio como necessidade de buscarmos estratégias uniformizantes de prevenção, esta entendida como mero controle, foge do acolhimento da atenção à singularidade; isso que escapa não é apreendido devido a uma lógica puramente generalista.

A atmosfera psicoterapêutica é fundamentalmente aquilo que se dá na experiência mesma do estar junto. $\mathrm{O}$ local e a organização são secundários aos modos de relacionar-se no encontro entre aquele que se disponibiliza a escutar e aquele que permite ser escutado. $\mathrm{O}$ acontecimento psicoterapêutico ocorre no processo de ressignificação.

Vida como abertura de possibilidades pode mostrar-se para aqueles que pensam em pôr fim ao próprio viver na medida em que a indeterminação existencial é a base da escuta. Desse modo, morte pode configurar-se de outro modo se a lida com a vida ganha outros sentidos.

Os desafios encontrados pelo LAFEPE são a incompreensão e a resistência de trazer para o debate o assunto do suicídio. Como grupo, pensamos que nosso agir só pode ser consumado na medida em que poder falar é entendido como gesto de suma potência para andar na contramão 
de vieses que moralizam antes mesmo de tentar entender quais elementos se fazem presentes na condição humana e sua vasta complexidade.

Poder ter participado em minha formação de um projeto desse porte certamente contribuiu para meu aprimoramento clínico, uma vez que cada atendimento e atividade realizada afinaram minha sensibilidade na tarefa de estar com o outro em situações de extrema delicadeza. Não só como acadêmico, mas também como cidadão tive a oportunidade de ver a educação sendo articulada democraticamente a serviço das diversas expressões de lida com a vida. $\mathrm{O}$ retorno à comunidade é a gratificação pelo serviço e, ao mesmo tempo, uma forma de resistência a todas as frentes que tentam desqualificar, barrar, ludibriar, apequenar e difamar o trabalho árduo e sério que a academia tem feito e oferecido. Existência engloba inevitavelmente vida e morte; portanto, apesar de escolher morrer também ser uma possibilidade, oferecer um espaço de acolhimento para que possibilidades outras possam ganhar forma é um modo de tornar o escolher viver algo maior que um mero vislumbre. Apostar na chance do viver como recomeço, respeitando a finitude como algo que é inelutavelmente nosso, é o contraponto diante da indiferença. O maior impacto que é oferecido à sociedade é despertar a ideia que acolher é acima de tudo caminhar junto.

\section{Considerações Finais}

A preciosidade da extensão nas universidades públicas nesse país é a expressão do vínculo entre as produções acadêmicas e a comunidade. O LAFEPE ao debruçar-se sobre o tema do suicídio busca pensar de modo profundo a relação indissociável entre viver e morrer. Dispor-se a acolher é reconhecer que vidas importam. Existência não possui um sentido em si, mas vários sentidos podem irromper a cada gesto que vida se resplandece, como uma obra de arte cuja fluidez prescinde de formas dadas. Minha formação em psicologia indiscutivelmente alcança patamares privilegiados por ter tido a oportunidade de ainda na graduação ter feito parte da resistência que é acreditar na educação como caminho para uma revolução social em nossa sociedade. Em tempos nefastos em que acreditar no ensino é balbúrdia, é um privilegio ser parte daqueles que acreditam que pensar é o que move um país. 


\section{Referências}

1. WHO. Newsroom - Suicide: one person dies every 40 seconds. World Health Organization. 9 de set. 2019. Disponível em: https://www.who.int/news-room/detail/09-09-2019-suicide-oneperson-dies-every-40-seconds. Acesso em 13 de dez. 2019.

2. SAÚDE, MISTÉRIO DA. Prevenção do suicídio: sinais para saber e agir. Suicídio. 2019. Disponível em: http://saude.gov.br/saude-de-a-z/suicidio. Acesso em 13 de dez. 2019.

3. CFP. Suicídio e os desafios para a Psicologia. Conselho Federal de Psicologia, Brasília: 2013.

4. FEIJOO, Ana Maria Lopez Calvo de. Por Um Núcleo de Atendimento Clínico a Pessoas em Risco de Suicídio, Rio de Janeiro, 2016. Disponível em: $<$ http://www.ifen.com.br/site/producoes-academicas/projetos/197-projeto-de-pesquisa-bolsaprodutividade-cnpq>. Acesso em: 13 de dez. 2019.

5. MINOIS, George. História do Suicídio: A sociedade ocidental perante a morte. Lisboa: Teorema Portugal, 1995.

6. FEIJOO, Ana Maria Lopez Calvo de. Suicídio entre o morrer e o viver: desmoralizando o suicídio na contemporaneidade. Rio de Janeiro: IFEN, 2018. 